\title{
Influence of pregelatinization on the physicochemical and compressional characteristics of starches obtained from two local varieties of Dioscorea rotundata
}

\author{
Bakre Lateef Gbenga ${ }^{1}$, Ogun Olakunle ${ }^{2}$ and Alayo Muinat Adedayo ${ }^{3}$ \\ ${ }^{1,2,3}$ Department of Pharmaceutics and Pharmaceutical Technology, Olabisi Onabanjo University, Sagamu, \\ Nigeria.
}

\begin{abstract}
This study investigates the effect of pregelatinization on the physicochemical and compressional characteristics of starches obtained from two local varieties of Dioscorea rotundata (gbongi and efuru) in comparison with corn starch, dicalcium phosphate and lactose. The physicochemical properties of the starches were evaluated using established methods while the compressional characteristics were analysed using density measurements, and the Heckel and Kawakita equations. The shapes range from polyhedral/rounded/oval in native and pregelatinized efuru starch to oval/ellipsoidal/rounded in the native and pregelatinized gbongi starch. The pregelatinized efuru starch was more spherical in shape than the native form. The pregelatinized starches have better flow than the native starches. Pregelatinization of gbongi starch resulted in an increase in bulk density while the reverse was the case for efuru starch. The native and pregelatinized efuru starches exhibited a type B behaviour while native gbongi starch and the pregelatinized form exhibited a type $C$ behaviour. Pregelatinization of the native starches resulted in a considerable reduction in $P_{y}$ value; even lower than the values for cornstarch and lactose. In addition, pregelatinization of gbongi starch resulted in an increase in $D_{o}$ value while a reduction was observed for efuru starch. The rank order of $P_{k}$ value was ENS $<G N S<$ Corn Starch $<E P G S<G P G S<$ Lactose $<D C P$. The pregelatinized starches are more plastically deforming than lactose. The results suggest that pregelatinization of the starches resulted in new functional and value added properties which could be explored in their use as pharmaceutical excipients in tablet formulation and production
\end{abstract}

KEYWORDS: Dioscorea rotundata, pregelatinization, gbongi and efuru starches, physicochemical properties, compressional properties

\section{INTRODUCTION}

In the pharmaceutical industry, excipients must have more functional properties than being just inert filler. Excipients are now essential parts of the drug delivery system in pharmaceutical tablets and they are generally used as diluent, binder, disintegrant, gliding agent, lubricant or release control agent. At a time when synthetic polymers and animal-based products are creating some concerns amongst the users, the need for natural excipients that are safe and versatile becomes more acute. Starches from various natural origins are wellknown, safe, and have been extensively investigated in pharmaceutical industry. They are mainly used in oral solid dosage forms as fillers, binders, or disintegrants. Starch is composed primarily of amylose and amylopectin, which are formed from glycosidic bonding of alpha-D-glucose units and, depending on its botanical source, some phosphorous, proteins and fats. Each starch constituent contributes to its intrinsic and binding properties. Starch has been isolated fron a variety of sources namely from plantain Musa paradisiacal [1]; African bitter yam Dioscorea dumentorum and White yam Dioscorea rotundata [2], from sorghum $S$. Bicolour [3]; pearl millet [4], sorghum [5], cassava and cocoyam, [6]; fonio Digitaria exilis [7].

The white or common yam, Dioscorea rotundata remains the principal yam cultivated in West Africa. Its cultivation has also spread to other parts of the world. It is grown extensively in the West Indies, and to some extent in East Africa. There are very large numbers of cultivars of D. rotundata that are grown, especially in West Africa. The tuber has a rough skin usually dark to light-brown in colour. The rough skin can be peeled with minimal degree of difficulty. The yam becomes edible only if it is well washed and properly cooked. These steps are necessary in order to reduce the anti-nutritional component of yam before consumption. White yam consists of starch, which is the only quantitatively important digestible polysaccharides being regarded nutritionally superior to low molecular-weight carbohydrate or sugar. In addition to being a major food item, it is currently used industrially as coatings and sizing in paper, textiles and carpets, as binders and adhesives, as absorbands and as encapsulants, bone replacement implants, bone cements, drug delivery systems, and tissue 
engineering scaffolds. However, in native state it exhibit limited applications due to low shear stress resistance and thermal decomposition, high retrogradation and syneresis, in addition to poor processability and solubility in common solvents. In addition, they possess sub-optimal intrinsic compressibility, fluidity and consistency of functional performance on a lot-to-lot basis. Therefore, to meet the demanding technological needs, the properties of starch are modified by a variety of methods with the aim of correcting some of these shortcomings and enhance its versatility and satisfy consumer demand. Although various modification techniques have been applied to several of the conventional and some unconventional starches, [8-11] it appears little or no work has been done to modify local varieties of yam (Dioscorea rotundata) starches. Hence this study was designed to study the effect of pregelatinization on the physicochemical and compressional properties of starch obtained from two local varieties (efuru and gbongi) of $D$. Rotundata.

\section{1}

\section{MATERIALS AND METHODS}

The materials used were dried powdered samples of two local varieties (efuru and gbongi) of Dioscorea rotundata starches, physically modified Dioscorea rotundata (efuru and gbongi) starches, corn starch and lactose (BDH Chemicals, UK), dicalcium phosphate (AB Knight and Co., London, UK) distilled water and every other chemical was of analytical grade.

\subsection{Methods}

\subsubsection{Preparation of yam starch}

Yam tubers were washed, peeled, trimmed to remove defective parts. The tubers were then sliced, diced and blended with distilled water in a food blender. The mixture was sieved through a sieving-cloth and the retained solids were exhaustively rinsed on the sieve with distilled water. The filtrate was allowed to stand overnight, the precipitate was collected and the supernatant was discarded. The re-suspension and sedimentation operations were repeated until white starch was obtained. The starch was dried in an oven at $50^{\circ} \mathrm{C}$ for 6 hours. Finally, using pestle and mortar, the dried yam-starch lumps were ground and the fine powder passed through a 250um mesh sieve. Yam starch was kept in a tight, light-resistant container.

\subsubsection{Preparation of pre-gelatinized yam starch}

$200 \mathrm{~g}$ of each native yam starch powder was weighed into a beaker. $300 \mathrm{ml}$ of distilled water was added to make slurry. The beaker was then placed over boiling water in a water-bath with continuous stirring for 5 minutes until a bright paste was formed. This was done in duplicate to increase the yield. The paste was poured on a tray and dried in an oven at $60^{\circ} \mathrm{C}$ to obtain a dried pre-gelatinized starch.

\subsubsection{Physicochemical properties of powder samples}

The identification test for starch, determination of moisture content, starch hygroscopicity and $\mathrm{pH}$ were done according to established procedures [12]. Microscopic examination of starch was done by mounting small quantity of the starch samples in glycerol on a light microscope.

\subsubsection{Determination of swelling capacity}

The swelling capacity was determined by a modification of the method Iwuagwu and Okoli [13]. Three grams of the starch powders were placed in $50 \mathrm{ml}$ ground-glass stoppered graduated cylinder. $20 \mathrm{ml}$ of water was added and the cylinder closed. This was shaken vigorously every 10 minutes for $1 \mathrm{hr}$. and then allowed to stand for $5 \mathrm{hr}$. At $2.5 \mathrm{hr}$. after the beginning of the test, any large volume of liquid retained in the layer of the sample and particles of the drugs floating at the surface of the liquid was released by rotating the cylinder about a vertical axis. The volume occupied by the sample including any adhering mucilage was noted. The swelling index was then calculated from the ratio of the volume occupied by the powder after swelling to the initial volume occupied by the powder after adding water. The test was performed in triplicate and the swelling capacity calculated from the mean of the three tests.

\subsubsection{Determination of Hydration capacity}

The procedure of Komblum and Stoopak [14] was used. Four hundred (400) mg starch samples were placed in each of $15 \mathrm{ml}$ plastic centrifuge tubes, distilled water was added from a $10 \mathrm{ml}$ measuring cylinder and then stoppered. The content was mixed on a vortex mixer for 2 minutes. The mixture in each tube was left for additional 3 minutes and the centrifuged at $500 \mathrm{rpm}$ for 20 minutes on a bench centrifuge. The supernatant was decanted and the sediment weighed. The weight of water absorbed and retained was determined as the gain in weight of the dry sample. Determinations were made in triplicate. 
Hydration capacity $\equiv$ (weight of tube + sediment $)$-weight sample Sample weight (dry basic)

\subsubsection{Determination of particle density}

The particle densities of the starch powder samples were determined by the pycnometer method using liquid immersion technique with xylene as the displacement liquid. A $50 \mathrm{ml}$ pycnometer bottle was weighed when empty (W). This bottle was filled with xylene to the brim till it overflows. The excess was wiped off the bottle and its contents were weighed $\left(\mathrm{W}_{1}\right)$. The difference between the two weights was calculated and recorded as $\left(\mathrm{W}_{2}\right)$. A $2 \mathrm{~g}$ quantity of each starch powder sample was weighed $\left(\mathrm{W}_{3}\right)$ and quantitatively transferred into the pycnometer bottle. The excess solvent was wiped off and the bottle weighed again $\left(\mathrm{W}_{4}\right)$. The particle density, $\rho$ $\left(\mathrm{g} / \mathrm{cm}^{3}\right)$, was calculated from the following equation:

$$
\rho_{\mathrm{s}}=\frac{\mathrm{W}_{2}+\mathrm{W}_{3}}{50\left(\mathrm{~W}_{1+} \overline{\mathrm{W}}_{3-}-\mathrm{W}_{4}\right)}
$$

The results given are the means of three determinations.

\subsubsection{Determination of bulk, tapped densities and powder porosity}

$20 \mathrm{~g}$ each, of individual starch powder samples respectively was poured through a short-stemmed glass funnel into a $50 \mathrm{ml}$ graduated glass cylinder and the unsettled apparent volume occupied by the starch powder noted. The bulk density $(\rho b)$ was calculated from the ratio of the mass of powder to the bulk volume. The determination was done in triplicate. Tapped density $(\rho t)$ was determined by dropping each graduated cylinder containing individual starch powder samples on a bench from a height of about $2 \mathrm{~cm}$ hundred times, and the respective volume recorded. The tapped density was taken as the mean of three determinations. The porosities of individual starch powder samples were determined using bulk $(\rho b)$ and true densities $\left(\rho_{s}\right)$ data as in Equation (3)

$\mathrm{e}=1-\rho \mathrm{b} / \rho_{\mathrm{s}} \times 100 \%$

\subsubsection{Determination of Flow properties}

The angles of repose $(\theta)$ of starch samples were determined using the funnel method [15]. A funnel was mounted on a laboratory stand at a fixed height above a graph paper placed on a horizontal surface. $10 \mathrm{~g}$ of starch samples was poured into the funnel with the tip closed. The tip-plug was removed and the starch was allowed to flow, the height and diameter of the starch heap were measured. The angle of repose, $\theta$, is given by the following equation:

$\theta=\tan ^{-1}(\mathrm{~h} / \mathrm{r})$

Where, $\mathrm{h}$, is height of conical heap and, $\mathrm{r}$, is the radius of the circular base.

The Hausner ratio, $\mathrm{H}$, of each sample was calculated as the ratio of the tapped density to the bulk density ( $\rho t / \rho b)$ while the compressibility index, $\mathrm{C}$, of each sample was calculated as below:

$\mathrm{C}=(\rho \mathrm{t}-\rho \mathrm{b}) / \rho \mathrm{t} \times 100 \%$

Where $\rho t$ is tapped density and $\rho b$ is bulk density.

Using Erweka Flow tester, $10 \mathrm{~g}$ each, of the individual starches respectively were allowed to pass through its orifice and the time taken was recorded. The flow rate $(\mathrm{g} / \mathrm{s})$ of each sample was calculated as the ratio of the mass of the powder to the time taken. Mean of the three readings was taken as the flow rate of the starches.

\subsubsection{FTIR Analysis}

$100 \mathrm{mg}$ of $\mathrm{KBr}$ (Potassium bromide) salt was weighed and mixed with grounded samples $(5 \mathrm{mg})$ uniformly. The samples were placed in an evacuable $\mathrm{KBr}$ die and a $13 \mathrm{~mm}$ clear disk was pressed in a hydraulic press which formed $\mathrm{KBr}$ pellets. The pelletized samples (which was formed inside the evacuated chamber) was placed in cell holders (universal demountable cell) and were inserted into the FTIR System (Spectrum BX, PerkinElmer, England) and scanned at a range of $350-4000 \mathrm{~nm}$. The spectrum was displayed on the computer screen and also the suspected compounds page. 


\subsubsection{Preparation of powder compacts}

Five hundred (500) $\mathrm{mg}$ of the powders were compressed for 30seconds into tablet with pre-determined loads using a hydraulic hand press (Model C, Carver Inc., Menomomee Falls,WJ). Before each compression, the die (12.5 $\mathrm{mm}$ in diameter) and the flat faced punches were lubricated with a $2 \% \mathrm{w} / \mathrm{w}$ dispersion of magnesium stearate in $96 \%$ ethanol. After ejection, the tablets were stored over silica gel for 24 hrs to allow for elastic recovery and hardening and to prevent false low yield values. The tablets weight and dimensions were determined within $\pm 1 \mathrm{mg}$ and $0.01 \mathrm{~mm}$ respectively. Their relative densities (D) were calculated using the equation.

$$
\mathrm{D}=\mathrm{W} /(\mathrm{vt} \times \mathrm{Ps})
$$

where vt is the volume of the tablets ( $\mathrm{cm} 2)$ and Ps is the solid material particle density $(\mathrm{g} / \mathrm{cm} 3)$. Heckel plots of In $(1 / 1-\mathrm{D})$ versus the compression pressure, $\mathrm{P}$ and Kawakita plots of $\mathrm{P} / \mathrm{C}$ vs. $\mathrm{P}$ was constructed. $\mathrm{a}$ and $\mathrm{b}$ are constants which are obtained from the slope and intercept of kawakita plots respectively. The reciprocal of $b$ is related to the pressure term, $\mathrm{P}_{\mathrm{k}}$, which is the pressure required to reduce the powder bed by $50 \%$ [16]. The precompression density (Do) was calculated as a ratio of the loose bulk density to the particle density.

Table 1 Powder characterization

\begin{tabular}{lllllllllllll}
\hline Sample & $\begin{array}{l}\text { True } \\
\text { density } \\
\left(\mathrm{g} / \mathrm{cm}^{3}\right)\end{array}$ & $\begin{array}{l}\text { Bulk } \\
\text { density } \\
\left(\mathrm{g} / \mathrm{cm}^{3}\right)\end{array}$ & $\begin{array}{l}\text { Tapped } \\
\text { density } \\
\left(\mathrm{g} / \mathrm{cm}^{3}\right)\end{array}$ & $\begin{array}{l}\text { Angle } \\
\text { of } \\
\text { repose } \\
(\mathrm{\circ})\end{array}$ & $\begin{array}{l}\text { Carr's } \\
\text { index } \\
(\%)\end{array}$ & $\begin{array}{l}\text { HR } \\
\text { rate } \\
(\mathrm{g} / \mathrm{s})\end{array}$ & $\begin{array}{l}\text { Porosity } \\
(\%)\end{array}$ & SC & WAC & $\begin{array}{l}\text { SI } \\
(\% \mathrm{w} / \mathrm{w})\end{array}$ & $\begin{array}{l}\text { SH } \\
(\%)\end{array}$ \\
\hline ENS & 1.459 & 0.4587 & 0.6579 & 34.55 & 30.28 & 1.43 & 0.07 & 68.60 & 1.25 & 34.2 & 2.1 & 3.1 \\
EPGS & 1.4752 & 0.3922 & 0.5814 & 27.91 & 32.54 & 1.48 & 0.20 & 73.40 & 1.14 & 30.1 & 1.9 & 4.4 \\
GNS & 1.4014 & 0.4854 & 0.6536 & 26.57 & 25.73 & 1.35 & 0.13 & 65.40 & 1.00 & 32.7 & 0.9 & 3.6 \\
GPGS & 1.361 & 0.5495 & 0.7337 & 22.88 & 25.11 & 1.34 & 0.48 & 59.60 & 1.33 & 27.8 & 1.0 & 1.1 \\
CS & 1.612 & 0.6404 & 0.8769 & 47.56 & 26.70 & 1.22 & 0.13 & 60.29 & 0.72 & 25.4 & 1.2 & 2.6 \\
DCP & 2.890 & 0.8151 & 1.2335 & 38.95 & 33.92 & 1.51 & 0.10 & 69.18 & 0.24 & 10.5 & 0.6 & 1.4 \\
LAC & 1.546 & 0.5196 & 0.7384 & 35.25 & 29.63 & 1.42 & 0.08 & 66.39 & 0.10 & 9.5 & 0.5 & 1.3 \\
\hline
\end{tabular}

ENS: Efuru native starch, EPGS: Efuru pregelatinized starch, GNS: Gbongi native starch, GPGS: Gbongi pregelatinized starch, CS: Corn starch, DCP: Dicalcium phosphate, LAC: Lactose, HR: Hausner ratio,WAC: Water absorption capacity, SC: Swelling capacity, SI: Solubility index, SH: starch hygroscopicity

Table 2: Parameters derived from Heckel and Kawakita plots

\begin{tabular}{lllll|cccr}
\hline \multirow{2}{*}{ Sample } & \multicolumn{4}{c|}{ Heckel Parameters } & \multicolumn{3}{c}{ Kawakita Parameters } \\
\cline { 2 - 8 } & $\mathrm{D}_{0}$ & $\mathrm{P}_{\mathrm{y}}$ & $\mathrm{D}_{\mathrm{A}}$ & $\mathrm{D}_{\mathrm{B}}$ & $\mathrm{a}$ & $\mathrm{D}_{\mathrm{I}}(1-\mathrm{a})$ & $\mathrm{b}$ & $\mathrm{P}_{\mathrm{K}}$ \\
\hline ENS & 0.3144 & 62.89 & 0.7793 & 0.4649 & 0.9807 & 0.0193 & 5.4 & 0.1852 \\
GNS & 0.3464 & 45.05 & 0.8951 & 0.5487 & 0.9813 & 0.0187 & 18.8 & 0.0532 \\
EPGS & 0.2659 & 8.97 & 0.7229 & 0.4570 & 0.9851 & 0.0149 & 7.2 & 0.1389 \\
GPGS & 0.4037 & 5.04 & 0.8506 & 0.4469 & 0.9802 & 0.0198 & 6.5 & 0.1538 \\
CS & 0.3971 & 11.10 & 0.6821 & 0.2950 & 0.9911 & 0.0089 & 9.3 & 0.1075 \\
DCP & 0.2820 & 27.25 & 0.6337 & 0.3517 & 0.9863 & 0.0137 & 2.6 & 0.3846 \\
LAC & 0.3361 & 11.05 & 0.7604 & 0.4243 & 0.9814 & 0.0186 & 5.8 & 0.1724 \\
\hline
\end{tabular}




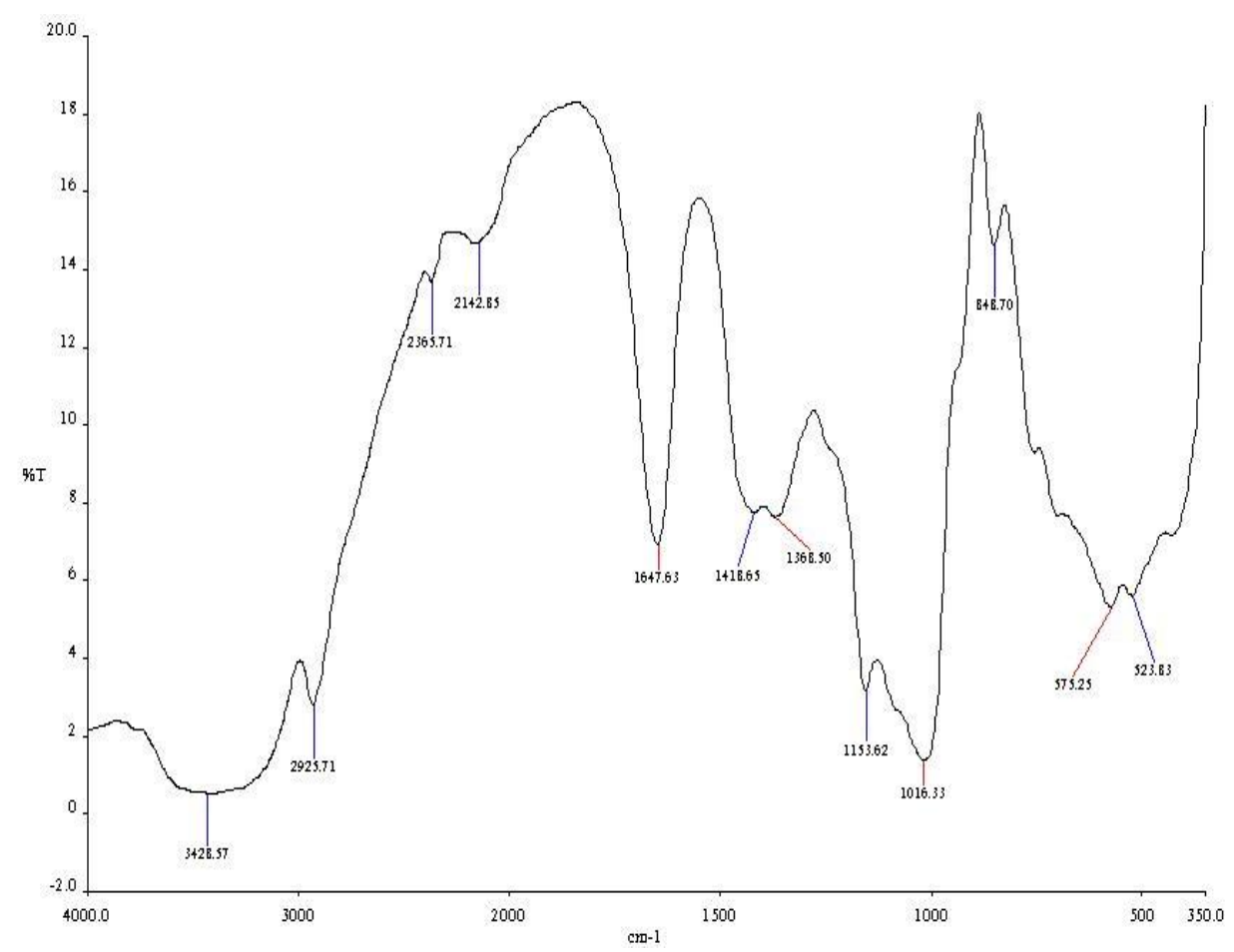

Figure 1: FTIR spectrum of native efuru starch

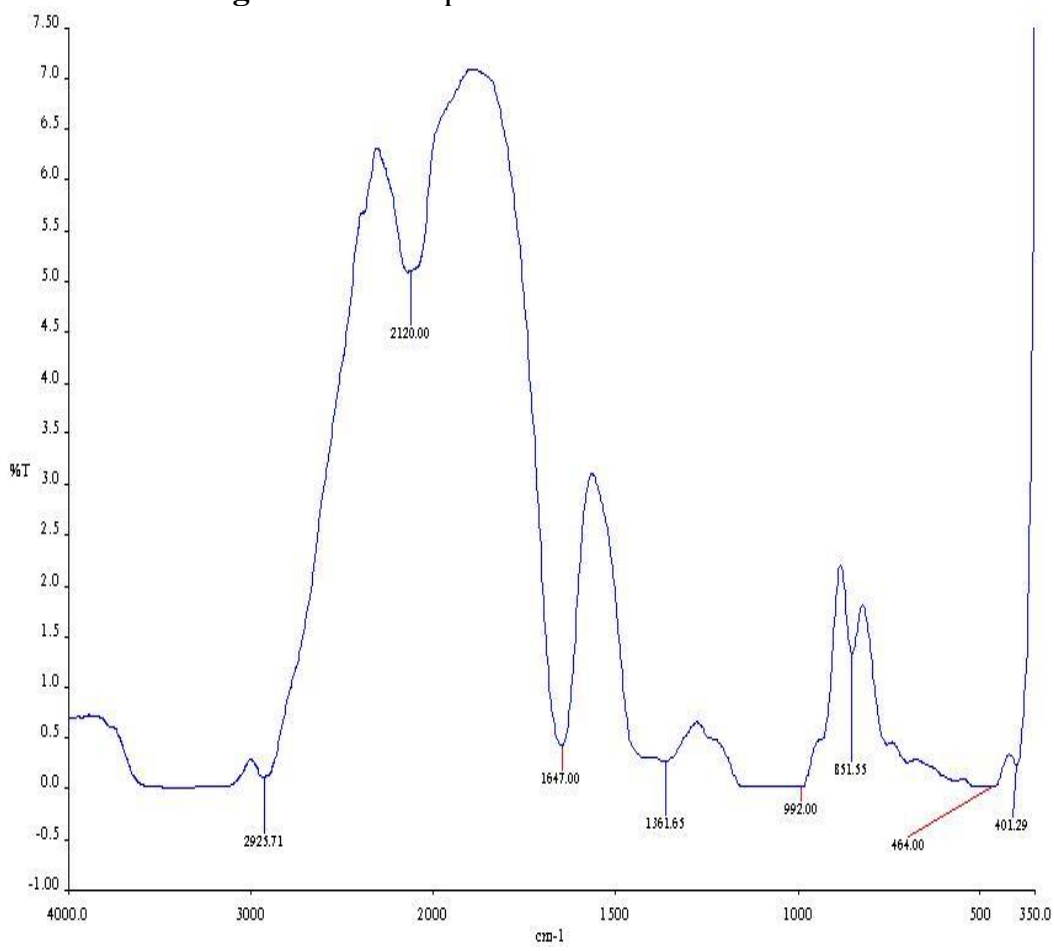

Figure 2: FTIR spectrum of pregelatinized efuru starch 


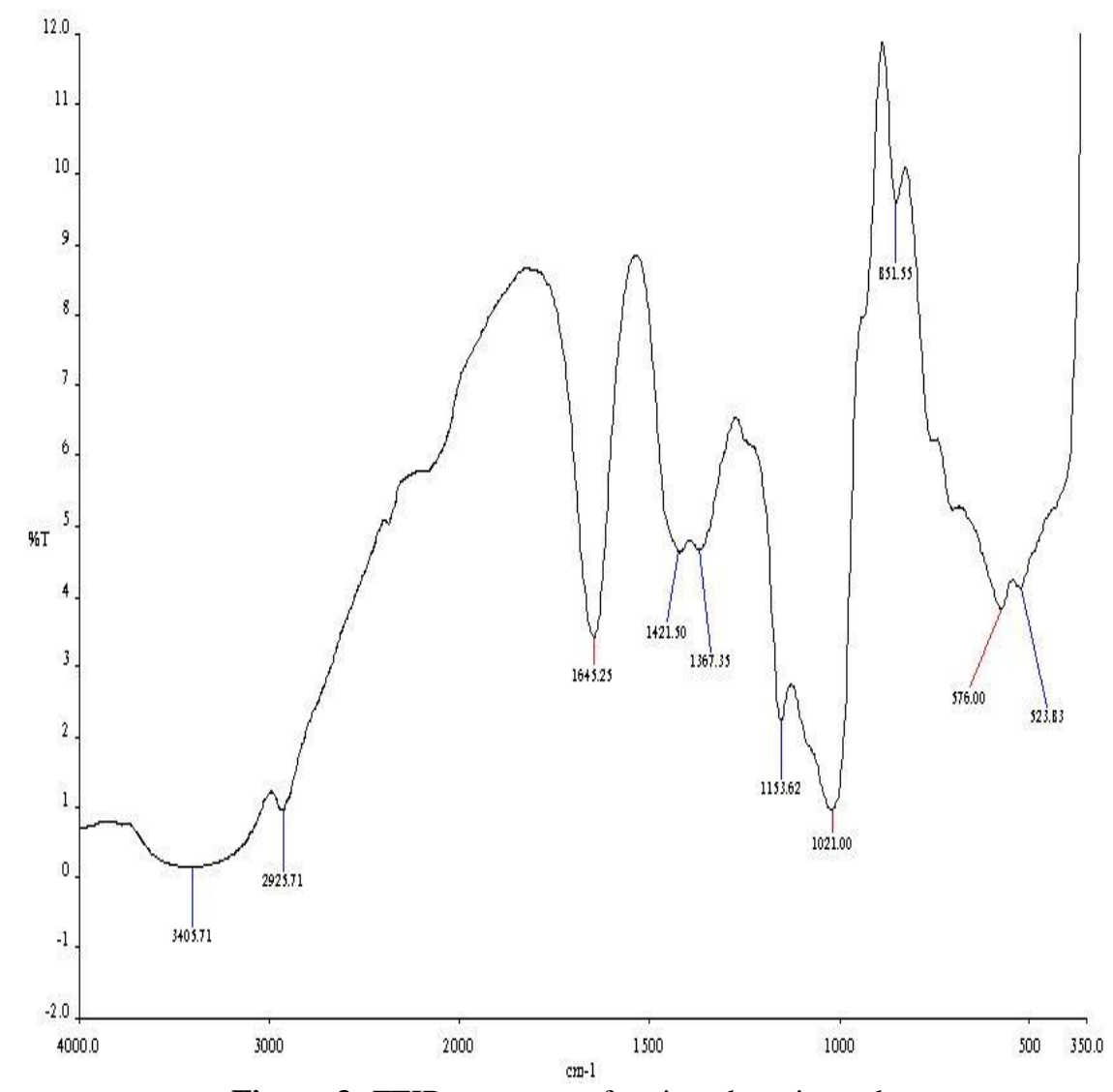

Figure 3: FTIR spectrum of native gbongi starch

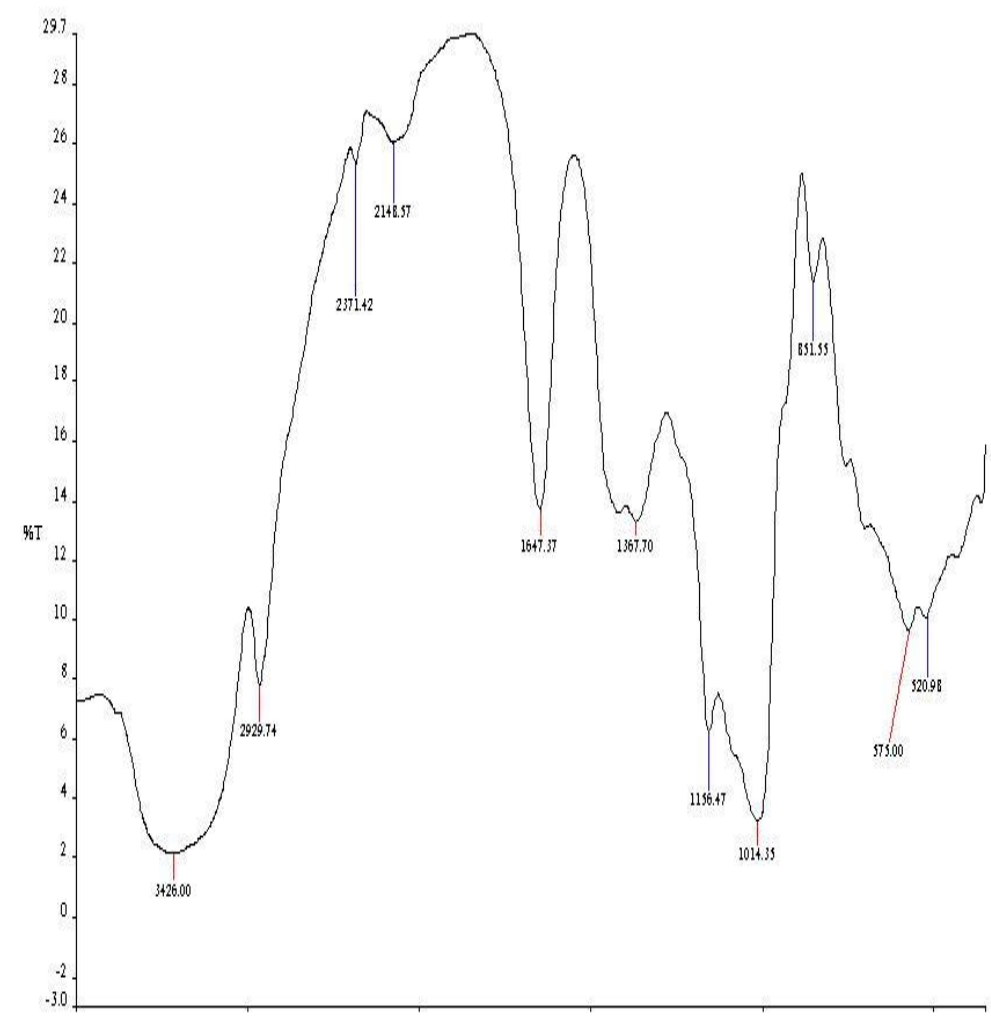

Figure 4: FTIR spectrum of pregelatinized gbongi starch 
A

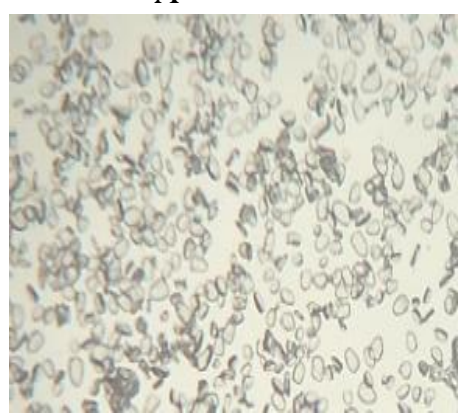

$\mathrm{C}$

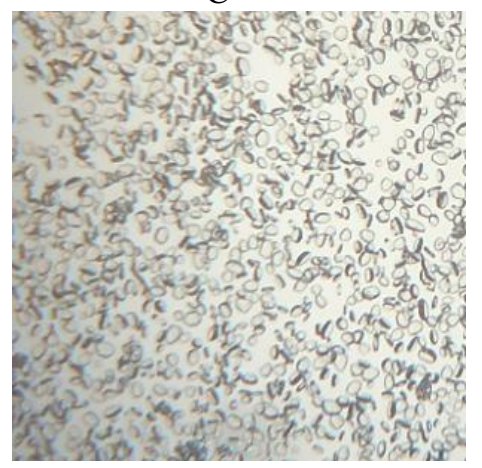

B

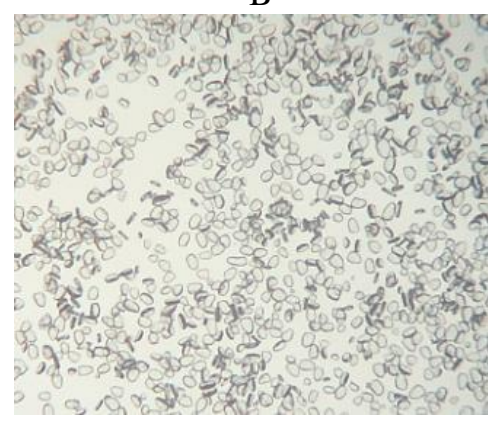

D

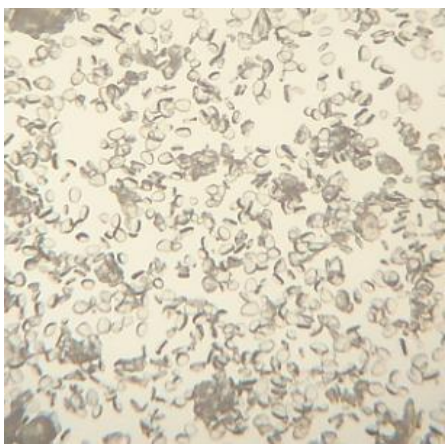

Figure 5: Photomicrograph of particles of starch powders (Mag. X 25)

A: Efuru native starch; B: Efuru pregelatinized starch; C: Gbongi native starch; D: Gbongi pregelatinized starch

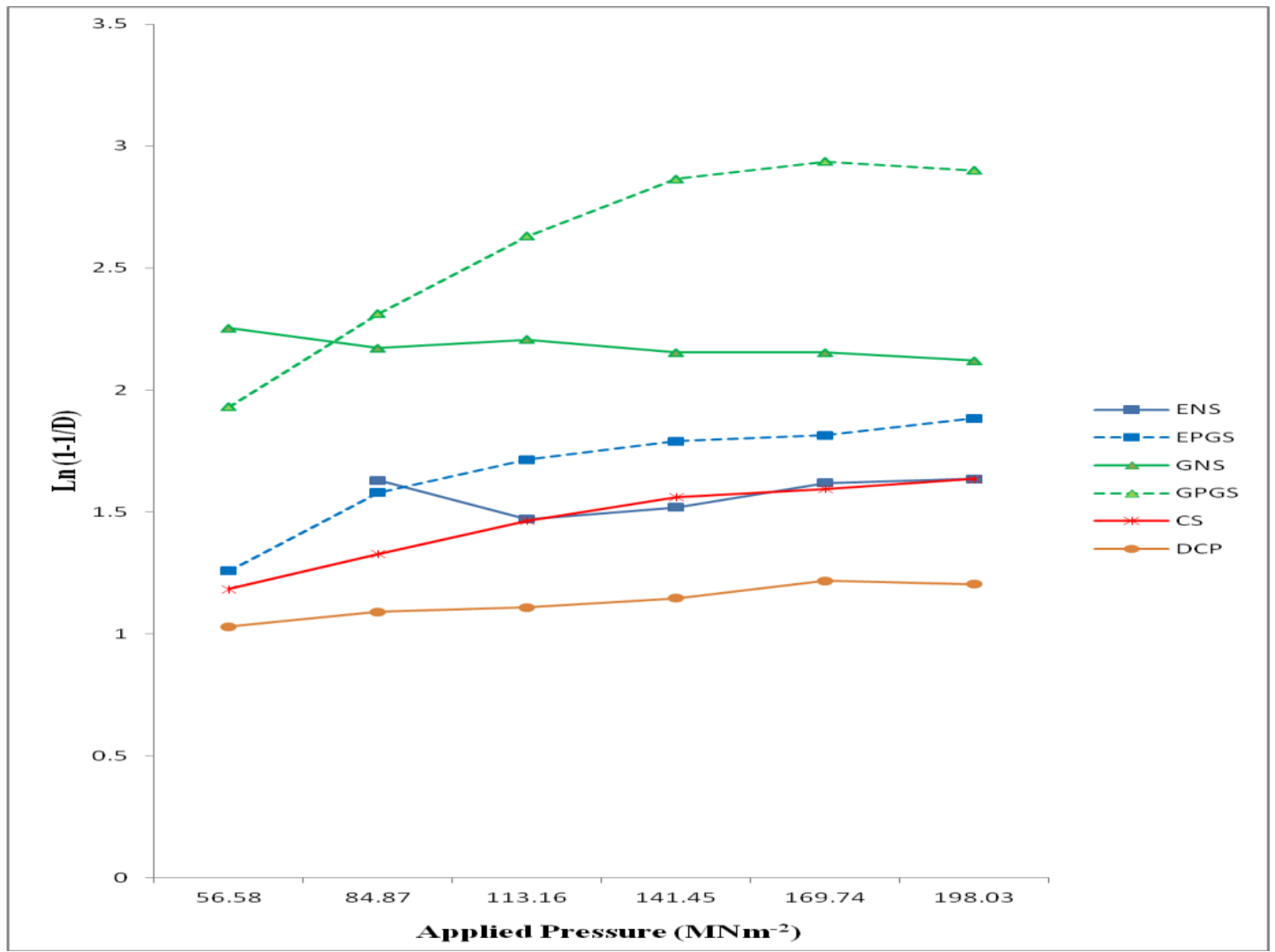

Figure 6: Heckel plots for native and pre-gelatinized starches 


\section{RESULTS AND DISCUSSION}

The packing and cohesive properties of starches influence the various aspects of powder processing such as milling, blending, flow from hoppers, compression and packing into capsule shells or containers. The packing and cohesive properties of starches depend to a large extent on the particle size distribution and shape [17]. The particle shape has been shown to influence the compaction characteristics since it affects the packing behaviour of the starches [18]. This is because there is a tendency for particle rearrangement to occur in the initial stages of the compaction process [19]. The morphological structures of the starches through light microscopy are shown in Fig. 5. The photomicrographs show that the shape of the native and pregelatinized, starches look considerably alike. The shapes range from polyhedral/rounded/oval in native and pregelatinized efuru starch to oval/ellipsoidal/rounded in the native and pregelatinized form of gbongi starch. It is noteworthy that the pregelatinized Efuru starch were more spherical in shape than the native form. These observed shapes were consistent with those reported in literature [20]. The powder characterisation results are presented in Table 1. The ranking of particle density, which is the true density of the material excluding voids was DCP>Cornstarch>lactose > EPGS > ENS $>$ GNS $>$ GPGS. The bulk density of a powder describes its packing behaviour during the various unit operations of tableting such as die filling, mixing, granulation and compression. Higher bulk density is advantageous in tableting due to reduction in the fill volume of the die. The ranking for the bulk density was DCP>cornstarch >GPGS >lactose> GNS >ENS > EPGS. Table 1 shows that pregelatinization of gbongi starch resulted in an increase in bulk density. The reverse was the case for efuru starch. The differences observed in the bulk density values of the native and pregelinized starches could be due to the different particle sizes and shapes which affected the packing arrangement of the powder particles. The smaller the size and/or the more spherical the shape of the powder particles, the higher will be the bulk density. The flow properties of a powder are essential to determine its suitability as a direct compression excipient. Powder flow phenomenon is complex and multi-dimensional depending on many powder characteristics and other factors [21]. Hausner ratio and Compressibility index are indirect methods of assessing the flow properties of powders [15]. The Hausner ratio indicates the degree of densification which could occur during tableting with the higher values predicting significant densification of powders. The rank order of the Hausner ratio values was DCP $>$ EPGS $>$ ENS $>$ lactose $>$ GNS $>$ GPGS. The angle of repose, $\theta$, could be used as a qualitative measure of the cohesiveness or the tendency of powdered or granulated materials to flow, for in stance, from hoppers through the feed frame into tableting machines. Such uniformity of flow will minimize weight variations in tablets produced [22]. Angles of $30^{\circ}$ or below are usually indicative of free flowing materials while an angle of $40^{\circ}$ or above indicates a poor flow. Table 1 show that the pregelatinized starches have better flow than the native starches. This is because pregelatinization causes substantial changes in the chemical and physical nature of the granular starch due to rearrangement of the inter and intra molecular hydrogen bonding between the water and starch molecules resulting in disruption or collapse of the molecular order within the starch granules. The infrared spectra of the native and pregelatinized starches are shown in Figures 1-4. The band stretch around $3420-3538 \mathrm{~cm}^{-1}$ in the pregelatinized gbongi starch is attributed to hydrogen-bonded hydroxyls on the starch molecules. The band at $2925-2933 \mathrm{~cm}^{-1}$ in both the native and pregelatinized efuru starches is attributed to $\mathrm{CH} 2$ symmetrical stretching vibrations. In the native efuru starch, the band at $1648 \mathrm{~cm}^{-1}$ is assigned to scissoring of two $\mathrm{O}-\mathrm{H}$ bonds of absorbed water molecules. The bands at $851 \mathrm{~cm}^{-1}$ is due to skeletal stretching vibrations of starch. The presence of sharp band at $575 \mathrm{~cm}^{-1}$ in the pregelatinized starches implies enhanced activity.

The Heckel plots are presented in Fig. 6. The plots of native and pregelatinized efuru starch are indicative of type B materials, exhibiting an initially curved region followed by a relatively straight line which implies that the particles are fragmenting at the early stages of the compression process. Native gbongi starch and the pregelatinized form exhibited a type $\mathrm{C}$ behaviour having an initial steep linear region which become superimposed and flatten out as the applied pressure is increased. This behaviour is ascribed to the absence of a rearrangement stage and densification is due to plastic deformation and asperity melting. The tendency of the material to deform either by plastic flow or fragmentation is described by the mean yield pressure , $\mathrm{P}_{\mathrm{y}}$, of the material which has been shown to be reciprocal of the slope, $\mathrm{K}$, of the Heckel plot obtain by the "ejected tablet method" [23]. It gives an impression of the ease of plastic deformation and softness of the materials. A faster degree of plastic deformation is reflected by a low $\mathrm{P}_{\mathrm{y}}$ value (steep slope) in a general sense [24]. The values of mean yield pressure, $\mathrm{P}_{\mathrm{y}}$, were calculated from the region of plots showing the highest correlation coefficient for linearity of $>0.997$ for all the starches (generally between $56.58-198.03 \mathrm{MNm}^{-2}$ ). The intercept, A, was determined from the extrapolation of this region. Values of $\mathrm{P}_{\mathrm{y}}, \mathrm{D}_{0}, \mathrm{D}_{\mathrm{A}}$ and $\mathrm{D}_{\mathrm{B}}$ for all the starches are presented in Table 2. The rank order of $\mathrm{P}_{\mathrm{y}}$ values is: GPGS < EPGS < lactose < cornstarch < DCP < GNS < ENS. The native starches have higher Py values than cornstarch and lactose. However, pregelatinization of the native starches resulted in a considerable reduction in Py value; even lower than the values for cornstarch and lactose. This suggests that the pregelatinized starches are softer and that the onset of plastic deformation in them occurred at much lower pressures. It is also notable that gbongi starch generally exhibited the lowest $P y$ values, whereas Efuru starch generally exhibited the highest $P y$ values. The relative density of the powder bed at the point when the applied pressure equals zero, $\mathrm{D}_{0}$, is used to describe the initial rearrangement phase of densification as a result of die filling [25]. Gbongi starch generally exhibited higher degree of initial packing in the die as a result of die filling. This could be attributed to the ovoid shapes of their particles which would facilitate closer, initial packing of the particles than the polygonal shapes of the particles of the other starches. In addition, pregelatinization of gbongi starch resulted in an increase in $\mathrm{D}_{\mathrm{o}}$ value while a reduction was observed for efuru starch. The value of $\mathrm{D}_{\mathrm{A}}$ represents the total degree of packing achieved at zero and low pressures as a result of rearrangement processes before an appreciable amount of inter-particulate bonding takes place. Pregelatinization of the starches resulted in a decrease in $D_{A}$. The ranking of $D_{A}$ was GNS $>$ GPGS $>$ EPGS> ENS > lactose>Corn Starch> DCP. $D_{B}$ values tend to indicate the extent of fragmentation of particles or granules, although fragmentation can occur concurrently with plastic and elastic deformation of constituent particles [26]. The native starches had the highest $D_{B}$ values which implied that their particles underwent a greater phase of re-arrangement in the early stages of compression. Table 2 highlights the parameters obtained from Kawakita plots of the starches. The value of $D_{I}$ is a measure of the packed initial relative density of the formulation with the application of small pressure or tapping. Both the native and pregelatinized starches had higher $D_{I}$ values than DCP and cornstarch The $D_{I}$ values for the starches were 
observed to be lower than the corresponding values of $D_{0} . P_{k}$ represents the pressure required to reduce the powder bed by $50 \%$ [16]. The value of $\mathrm{P}_{\mathrm{k}}$ provides an inverse measure of the amount of plastic deformation occurring during the compression process. Low values indicate that the materials are soft and readily deform plastically under pressure. The rank order of $\mathrm{P}_{\mathrm{k}}$ value was ENS $<$ GNS $<$ Corn Starch $<$ EPGS $<$ GPGS $<$ Lactose $<$ DCP. Pregelatinization of the native starches resulted in a decrease in $\mathrm{Pk}$ value for Efuru starch and an increase for gbongi starch. This suggests that pregelatinized efuru starch are more soft and readily deform plastically than pregelatinized gbongi starch. All the pregelatinized form are more plastically deforming than lactose. Cornstarch is an example of a model plastic material. Both the native efuru and gbongi native starches exhibited lower Pk value than cornstarch.

\section{CONCLUSION}

The results of the study provided an insight into the material, compressional and tablet properties of the native and pregelatinized Dioscorea starches. It also shows that pregelatinization of the starches resulted in new functional and value added properties which could be explored in their use as pharmaceutical excipients in tablet formulation and production.

\section{REFERENCES}

[1] S. Esezobo, Evaluation of Sweet Potato Starch as binder and disintegrant for paracetamol tablet, Nig. Journal of Pharm. Sci., 2(2), 1986, $44-51$

[2] O. Malomo and A. A. Jayeola, Micromorphological and chemical characterization of starches in Dioscorea rotundata L. (White Yam), Not. Bot. Hort. Agrobot. Cluj, 38 (1), 2010, 14-20

[3] A. V. Deshpande and L.B. Panya, Sorgum Starch as a tablet excipient, J. Pharm. Pharmacol, 39,1987, 495-500

[4] O.F. Akande, J.L. Ford, P.H. Rowe and M.H. Rubinstein, 1998. The effects of lag time and dwell time on the compaction properties of 1:1 paracetamol / microcrystalline cellulose tablets prepared by pre-compression and main compression. J. Pharm. Pharmacol. 50, 1998, 19-28

[5] J.S.M Garr and A.B. Bangudu, Evaluation of sorghum starch as a tablet excipient. Drug Dev. Ind. Pharm, 17(1), 1991, $1-6$.

[6] Kunle, O.O., The effects of some local starches on the properties of granules and tablets, Master Thesis, Ahmadu Bello University, Zaria, Nigeria, 1988

[7] J. Muazu, H. Musa and P.G. Bhatia, Evaluation of the glidant property of fonio starch, Research Journal of Sciences, Engineering and Technology 2(2), 2010, 149-152

[8] J. Singh, L. Kaur and N. Singh, Effect of acetylation on some properties of corn and potato starch, Starke, 56(12), 2004,586-601

[9] O.S. Lawal, Composition, physicochemical properties, retrogradation properties of native, oxidized, acetylated, acid thinned new cocoyam (Xanthosoma sagittifolium) starch, Food chemistry 2004, 87, 205-218

[10] L. Tuovinen, S. Peltonen, and K. Jarvinen, Drug release from starch films, Journal of Controlled Release, 91, 2003, 345-354.

[11] C. Calinescu Carmen et al. "Carboxymethylated high amylose starch (CM-HAS) Excipient for Escherichia coli oral formulations, European Journal of Pharmaceutics and Biopharmaceutics, 60, 2005, 53-60.

[12] British Pharmacopeia (2002): Her Majesty's Stationary Office, London.

[13] M.A. Iwuagwu and P.C. Okoli, The disintegrant properties of pregelatinized cassava and white yam starches. Pharm. World J. 9, 1992, $49-53$.

[14] S.S. Komblum and S.B. Stoopak, A new tablet disintegrating agent: cross-linked polyvinylpyrollidone. J. Pharm. Sci. 62, 1973, 43-48

[15] Staniforth, J. N. 2000. Powder flow. In: Pharmaceutics: The science of dosage form design. Aulton M. L. ed. ELBS. 600-615

[16] P. Shivanand and O. L. Sprokel, Compaction behaviour of cellulose polymers, Powder Technol., 68, 1992, 177-184.

[17] O.A. Itiola and O.O. Odeku, Packing and cohesive properties of some locally extracted starches, Trop J. Pharm Res, $4(1), 2005,363-368$

[18] Odeku, O. A. and Itiola, O. A, Evaluation of khaya gum as a binder in a paracetamol tablet formulation. Pharm. Pharmacol. Commun. 4, 1998, $183-188$.

[19] P.E. Wray, The physics of tablet compaction revisited. Drug Dev. Ind. Pharm., 18, 1992, 627-658.

[20] N,G Amani, A. Bulẽon, A, Kamenan and P. Colonna, Variability in starch physicochemical and functional properties of yam (Dioscorea sp) cultivated in Ivory Coast. J.Sci. Food Agric. 84(15), 2004, 2085-2096.

[21] J.K. Prescott and R.A. Barnum, Powder flowability. Pharm. Tech. 24(10) 2000, 60 - 84

[22] S. Varthalis and N. Pilpel. Anomalies in some properties of powder mixtures, J. Pharm. Pharmacol. 28, 1976, 415 419.

[23] H. Kim, R. Fasshihi and G. Venkatesh, Compactibility characterization of granular pectin for tableting operation using a compaction simulator. Int J. Pharm,161 (2), 1998, 149-59.

[24] C.Y. Isimi, R.N. Nasipuri, J.B. Ojile, Y.K.E Ibrahim and M. Emeje, Effects of the diluent type on compressional characteristics of the mixed stem bark extract of Anogeissusleiocarpus and Prosopis Africana tablet formulation, Acta Pharm, 53, 2003, 49-56.

[25] L.G. Bakre and K.T. Jaiyeoba K, Effect of drying methods on the physicochemical and compressional properties of Okra powder and the release properties of its Metronidazole tablet formulation. Arch. Pharm. Res. 32(2), 2009, 259267.

[26] O.A. Odeku, O.O. Awe, B. Popoola, M.A. Odeniyi and O.A. Itiola, Compression and mechanical properties of tablet formulations containing corn, sweet potato, and cocoyam starches as binders. Pharmaceutical Technology 29 (4), 2005, 82-90. 